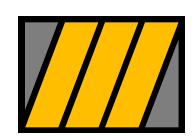

ESCUELA DE NEGOCIOS Universidad Torcuato Di Tella centro de investigación en finanzas

Documento de Trabajo 04/2008

\title{
Sovereign Defaults: Information, Investment and Credit
}

\author{
Guido Sandleris \\ UTDT and Johns Hopkins University
}

Almirante Sáenz Valiente 1010 C1428BIJ Buenos Aires • Tel: (54 11) 5169.7300

Fax: (54 11) 5169.7347 - Web site: http://www.utdt.edu 


\title{
Sovereign Defaults: Information, Investment and Credit*
}

\author{
Guido Sandleris ${ }^{\dagger}$ \\ Universidad Torcuato Di Tella and Johns Hopkins University
}

July 24, 2008

\begin{abstract}
Why would a sovereign government, immune from bankruptcy procedures and with few assets that could be seized in the event of a default, ever repay foreign creditors? And, correspondingly, why do foreign creditors lend to sovereigns? This paper finds general conditions under which, even in the absence of sanctions, lending to sovereigns can emerge in a single shot game. Furthermore, it shows that positive borrowing can be sustained both in pooling and separating equilibria. In this way, it makes clear that neither sanctions nor reputation considerations, the two classical explanations, are necessary to enforce repayment. Information revelation is the crucial mechanism for these results. The repayment/default decision is interpreted as a signal used by the government to communicate information to domestic and foreign agents about the fundamentals of the economy. Governments repay to affect agents' expectations about them. A default, through its effect on expectations about fundamentals, can generate a decline in foreign and domestic investment and a credit crunch in domestic credit markets. Governments repay to avoid these costs, but may default (in equilibrium) when hit by a negative shock.
\end{abstract}

JEL Classification codes: F34, F30, G15

Key words: sovereign debt, sovereign default, reputation, sanctions, signaling

${ }^{*}$ I am grateful to Don Davis for his guidance and support. For their useful comments and suggestions, I also want to thank Manuel Amador, Jean Boivin, Alessandra Casella, Ron Findlay, Alberto Martin, Rick Mishkin, Veronica Rappoport, Paolo Siconolfi, Filippo Taddei, Mike Woodford and seminar participants at Harvard University, Columbia University, Johns Hopkins University, IADB, Universidad Di Tella, Universidad de San Andres, CUNY and Boston Fed. I also benefited from the suggestions made by the editor and two anonymous referees. All remaining errors are my own.

${ }^{\dagger}$ Escuela de Negocios, Universidad Torcuato Di Tella and SAIS, Johns Hopkins University, Address: Alte Saenz Valiente 1010, Buenos Aires, Argentina, CP1428, email: gsandleris@utdt.edu, te: (54) 11 5169 7301, fax: (54) 11 51697347 


\section{INTRODUCTION}

In January 2003 Luiz Inacio "Lula" Da Silva was sworn in as President of Brazil. Soon afterwards, Lula's government undertook an adjustment in public expenditures that dented its popularity. The main purpose of this adjustment was to restore Brazil's fiscal health and avoid a default on its debts. In this way, Lula's government tried to prevent Brazil from following the path of Argentina which defaulted on its sovereign debt not long before, in December 2001. Why did the Brazilian government choose to repay its external debts instead of enjoying the "instant gratification" of a default?

This question arises due to the weak legal framework of sovereign debt. The legal enforceability of sovereign debt contracts is very limited. Sovereign governments are immune from bankruptcy procedures and few of their assets could be seized in the event of a default. So, why did Lula's government choose to repay? And, in general, why would governments ever repay foreign creditors? Correspondingly, why do foreign creditors lend to them? This is the puzzle that the sovereign debt literature has been studying since Eaton and Gersovitz (1981) and that I will address in this paper.

The question is very simple and has generated a vast literature. The overwhelming majority of suggested explanations fall into two categories: sanctions and reputation. Sanctions-related explanations rely on the ability of creditors to impose sanctions (usually trade-related) to punish a defaulting government. The standard reputation argument relies on the ability of creditors to exclude a defaulting government from credit markets. However, Bulow and Rogoff (1989a) showed that for this threat to enforce repayment, it is necessary to assume as well that governments cannot save using a sufficiently rich set of assets following a default. Otherwise, there will always be a point in time when the government would find it optimal to default and begin a sequence of savings that replicates the payoffs of the original contract but generates extra income. ${ }^{1}$

There has been a recent revival of the credit market exclusion story in response to Bulow and Rogoff's critique. The arguments have focused on two assumptions required for their result, namely the availability of a rich enough set of assets following the default and the ability of the government to save optimally. Kletzer and Wright (2000) and Wright (2002) argued that the set of assets becomes endogenously restricted if banks could default too or collude. Amador (2003) showed how a political economy problem may lead to myopic government behavior and, therefore, suboptimal savings. ${ }^{2}$

My paper suggests an explanation to the puzzle that is based neither on sanctions nor on the

\footnotetext{
${ }^{1}$ See Eaton and Fernandez (1995) for a detailed review of the early reputation and sanctions arguments. The reputation argument has also been applied to intra-national lending in situations where commitment is not possible by Kocherlakota (1996), and Ligon, Thomas and Worrall (2000) among others.

${ }^{2}$ There have been few attempts to test empirically the alternative theories of the costs of sovereign default, and the results have been mixed. See Martinez and Sandleris (2005) for a more detailed analysis of this issue.
} 
exclusion from credit markets. Information revelation is the crucial element. Debt repayment acts as a signal sometimes used by governments to reveal information and influence foreign and domestic investors' expectations. In contrast, a sovereign default, through its effect on expectations, may have a widespread effect on the domestic economy, generating costs in terms of output and welfare.

A contribution of the paper is to find general conditions under which this signaling story could provide incentives to repay and, therefore, support some positive level of sovereign debt. In particular, this paper shows that the signaling argument can act as an enforcement mechanism in a finite horizon model without a repeated game argument behind it. In this context, positive borrowing can be sustained both in pooling and separating equilibria.

In order to emphasize the role that information revelation might play, I build a model that rules out by construction the prior explanations. The government borrows to produce a public good and will be able to borrow at most once regardless of whether it chooses to default or not, so the threat of exclusion from credit markets cannot enforce repayment, and neither can any other reputation story. Furthermore, I assume that creditors cannot impose sanctions in the event of a default.

The basic structure studied in this paper is one in which the government is privately informed about some variables that might be relevant for private sector decisions such as its willingness or ability to undertake structural reforms, deal with corruption or protect property rights (i.e.: some of the fundamental institutions of an economy). Private sector actions affect the government welfare function and depend on private sector agents' beliefs about the government's private information. As a result, the government may use its repayment/default decision to signal this information to the private sector and influence their beliefs and actions. It is important to emphasize that for the purpose of this paper, the information of the government about the fundamentals does not need to be better than that of the private sector, it just needs to be different and relevant.

Several possible illustrations of this sort of signalling story can be presented. For example, the level of foreign direct investment might depend on the expected improvement in the fundamental institutions of the economy (i.e. corruption, property rights, etc), and the government might have some private information about its own ability or willingness to undertake the structural reforms required to improve them. So, if the government welfare increases in the level of output generated by foreign investment, then a "good" government might need to signal its superior ability to improve institutions through a costly signal that a "bad" government will choose not to undertake, such as repaying its debt. Another illustration could be one in which a set of domestic entrepreneurs about which the government cares, needs to borrow from abroad to finance their investment and they are constrained by the amount of collateral they have. The expected value of this collateral depends on the realization of the fundamentals of the economy. The government has private information about them and may undertake the costly action of repaying foreign creditors in order to signal 
the existence of good fundamentals.

Repayment is one of the many possible signals that a government may undertake to influence expectations. However, just communicating the information to the private sector (i.e.: just telling them) is usually not one of them. The reason is that the government faces a credibility problem. In the model, the government's welfare is higher the higher the level of the private sector action, which in turn is positively related to beliefs about the government's private information. This means that regardless of the realization of its private information, the government would, in general, like to induce the highest possible beliefs if doing so is costless. An interesting characteristic of the model is that the presence of alternative costly signals might reduce welfare. The reason is that if other signals exist, then the amount of repaying that the government could "commit" itself to make will be reduced and, as a result, creditors will reduce the amount of lending, limiting the production of public goods.

In the model defaults occur in equilibrium, and only when fundamentals are worsening (i.e.: "bad" government). A crucial ingredient for this result is that the gains from repaying are increasing in the fundamentals. This occurs because the productivity of capital is higher when fundamentals are better, and, therefore, the gains of affecting beliefs through repayment and having higher levels of investment will be larger. On the other hand, the cost of repaying with standard debt instruments is either invariant or decreasing in the fundamentals. This is what generates the single crossing property in the model. For a given level of debt, a separating equilibrium could arise in which a "good" government may choose to repay rather than default and suffer a decline in the output generated by foreign investors, while a "bad" one might choose the opposite as the decline in output would be smaller. However, for relatively lower levels of debt a pooling equilibrium in which both the "good" and the "bad" government would choose to repay. In equilibrium, foreign creditors will limit the amount of lending to the government, so that the government finds it optimal to repay at least for some realizations of the fundamentals. The interest rate on the government debt will reflect the default risk.

Although the contributions of this paper are essentially conceptual, the predictions of the stories suggested in the paper are consistent with a number of stylized facts. Following a default the model predicts a decline in private sector investment and credit to the private sector, facts that have been repeatedly documented. In my model, these, in turn, trigger a decline in output, which is again an usually observed fact in the aftermath of defaults. ${ }^{3}$ The model also predicts that when the probability of worsening fundamentals increases so does the interest rate on sovereign bonds, which also is consistent with the empirical evidence. ${ }^{4}$

In order to gain some additional insight into the basic idea behind the model, it is interesting to briefly analyze Lula's government decision not to default. The months prior to Lula's election were

\footnotetext{
${ }^{3}$ See Chuhan and Sturzenegger (2003) or IMF (2002) for an analysis of the effects of recent default events.

${ }^{4}$ See Eichengreen and Mody (1998) for empirical evidence on this regard.
} 
characterized by a tremendous amount of uncertainty and concerns for investors and entrepreneurs (both Brazilian and from abroad). ${ }^{5}$ In particular, there were worries about Lula's government's attitudes towards issues such as property rights, privatizations and the business environment in general. Even the more optimistic observers worried about the Workers' Party ability to run an efficient government. ${ }^{6}$ Once elected, Lula tried to dissipate these concerns, and debt repayment was an important component of the strategy. Lula's government undertook a costly fiscal adjustment to be able to make its debt payments. Although not the only feasible explanation, it can be argued, as my model does, that repaying foreign creditors was one of the costly signals that Lula's government had to undertake in order to improve investors' and entrepreneurs' expectations. Had he chosen to default, the negative effect on expectations and the economy would have been substantial. Although more general, this could be a good example of the sort of story that the model tries to capture.

The information mechanism presented in this paper is related to Cole and Kehoe's (1998) "reputation spillovers" argument in that the costs of defaults arise outside the government/foreign creditors relation. In effect, Cole and Kehoe aimed to resurrect the reputation story by arguing that a default may affect the government reputation in other trust-based relations in which it could be involved. However, their focus on reputation prevented them from articulating the more important and direct role that information and signaling could play. In contrast, this is the crucial component in this paper. As the model makes clear this information channel exists even in a finite horizon where reputation stories would unravel.

The model is related to those in the reputation literature in which defaults affect beliefs such as Cole, Dow and English (1995) or Eaton (1995). This last paper also shares with my paper the feature of involving a finite horizon model. However, in these papers the only consequence of this effect on beliefs is to trigger the exclusion of the government from credit markets. In other words, the signaling component just plays a role in explaining why governments are excluded from the market. And, it is this exclusion that really enforces repayment. As explained, the threat of exclusion from credit markets plays no role in my model.

The paper is structured as follows. Section 2 presents the model with foreign direct investors. Section 3 derives the main result of the paper, namely that positive sovereign borrowing could arise even in the absence of sanctions or reputation arguments, and Section 4 concludes.

\footnotetext{
${ }^{5}$ The Brazilian stock market, the exchange rate, and government debt reflected these concerns. From the beginning of 2002 until the elections in October, the Brazilian stock market index lost a third of its value, the nominal exchange rate depreciated more than $60 \%$, and Brazil's sovereign risk soared to break the 2000 bps mark.

${ }^{6}$ See Gavin and Werneck (2002) or The Economist (2002) for examples of investors' concerns during this period.
} 


\section{THE MODEL}

\subsection{Environment}

There are three type of agents in the model: the government, foreign creditors, and a continuum of mass 1 of a "third party" of economic agents, which could be thought of, for example, as foreign investors. The world lasts for three periods, $t=0,1,2$. The general environment studied in this paper is summarized in Table 1.

\begin{tabular}{|c|c|c|}
\hline $\mathbf{t}=\mathbf{0}$ & $t=1$ & $t=2$ \\
\hline $\begin{array}{l}\text { - Foreign creditors } \\
\text { determine max lending to } \\
\text { govt. and interest rate } \\
\text { - Govt. borrows from } \\
\text { foreign creditors and } \\
\text { produces public good }\end{array}$ & $\begin{array}{l}\text { - Govt. receives private information } \\
\text { about fundamentals (good with } \\
\text { probability } \mathrm{p} \text {, bad with probability 1- } \\
\text { p) } \\
\text { - Govt. defaults or repays its debts } \\
\text { using exogenous revenues } \\
\text { - Foreign creditors and third party } \\
\text { agents update beliefs: } \mathrm{p}^{\prime}=\mathrm{p}^{\prime}(\mathrm{x}) \\
\text { - Third party action }(a) \text { depends on } \mathrm{p}^{\prime}\end{array}$ & $\begin{array}{l}\text { - Payoffs take place (govt. } \\
\text { payoff depends on } a \text { ) }\end{array}$ \\
\hline
\end{tabular}

Figure 1:

The government borrows from foreign creditors at time 0 to finance the production of a public good. At time 1 the government gets to know the fundamentals $\theta$, while other agents in the economy only know the probablity distribution of the fundamentals: $\operatorname{good}(\bar{\theta})$ with probability $\mathrm{p}$ and bad $(\underline{\theta})$ with probability 1-p. ${ }^{7}$ This assumption tries to capture the fact that governments, particularly in developing countries, might have some private information that affect private sector actions. This information could be related, for example, to their own ability or willingness to deal with corruption or implement structural reforms that may enhance some fundamental institutions of a country such as the respect of property rights or the rule of law.

\footnotetext{
${ }^{7}$ Note that, at the cost of some additional notation, we could have the government and the investors both receiving noisy signals about the fundamentals. The relevant assumption in such an environment for the results of the model to carry over would be that the government's information is different and relevant for investors.
} 
After observing its private information about the fundamentals, the government chooses whether to repay its debt with foreign creditors $(x=1)$ or to default $(x=0)$. The government makes this decision being aware that economic agents might update their beliefs on fundamentals being good from p to p' based on the government action. Posterior beliefs, p', matter as they will affect some third party action $(a)$ about which the government cares. In order to make the presentation of the model more intuitive I will focus on an example that seems relevant for the case of emerging countries, namely that the "third party action" is the level of foreign direct investment. ${ }^{8}$ Finally, at time 2 output is produced and consumption take place. ${ }^{9}$

In order to motivate sovereign borrowing, I will assume that the only way in which the government can finance the production of public goods is by borrowing from abroad. However, financial markets are incomplete and foreign creditors, which are assumed risk neutral, only offer to the government standard, non-contingent debt contracts. These contracts are not collateralized in any way. These assumptions are consistent with real world sovereign debt contracts. ${ }^{10}$ Repaying is costly for the government as it involves transferring resources to foreign creditors whose welfare does not enter into the government welfare function.

It is assumed that creditors cannot impose sanctions on the government following a sovereign default. The timing of government borrowing and the maturity structure of the sovereign debt described above will arise endogenously in the model as a result of this assumption. In effect, as the world ends at time 2 , there are no reputation considerations in terms of future market access to take into account at that time. Furthermore, as there are no agents making decisions at that time the government does not need to worry about affecting agents' expectations through a default, and as there are no sanctions either, the government will never have an incentive to make a payment at time 2. As a result, foreign creditors will never offer the government debt contracts that mature at time 2. This implies that foreign creditors will never lend to the government at time 1 , regardless of whether the government has defaulted or repaid its time 0 debts (if any) at time 1 . So, the government will only be able to borrow at most once, at time 0 and the debt contracts will mature at time 1, exactly as descibed above. It is important to emphasize that, when the government has to make its repayment decision at time 1 reputation considerations will play absolutely no role either as the government knows that it will not be able to borrow again. That is, the threat of exclusion of the government from credit markets upon default cannot enforce sovereign debt repayment at

\footnotetext{
${ }^{8}$ Under an alternative interpretation, the "third party" action could be the amount of investment that creditconstrained domestic entrepreneurs can undertake. Better beliefs about the fundamentals may relax the domestic entrepreneurs ' credit constraint.

${ }^{9}$ The fact that the third party action takes place after the government repayment/default decision is not a strong assumption as there are a myriad of decisions that are influenced by fundamentals that are made almost all the time in the real world. So, for example there will always be some investment decisions made after the government repayment/default decision.

${ }^{10}$ Alternatively, one could think of this model as just trying to explain the uncollateralized part of sovereign borrowing.
} 
time 1 either.

The main reason for choosing a three period setup without sanctions is to show clearly where the results of the model are coming from. In the absence of sanctions or reputation considerations, the sovereign borrowing literature would suggest that the only equilibrium for the model would be one with zero lending to the government. However, by imposing some information structure to this simple model I show that this is not necessarily the case.

If foreign creditors were to lend to the government $b$ units of the good at time 0 , they would obtain $x R b$ when the contract expires at time 1 , where $R$ is the gross interest rate on sovereign debt and $x$ is an indicator variable that captures the government default decision (i.e.: $x \in\{0,1\}, x=0$ if the government defaults and $x=1$ if the government repays). That is, if the government defaults it will not repay anything. This assumption is extreme as it excludes any possible renegotiation that could generate a positive repayment to foreign creditors upon default, which is what we usually observe in reality. In principle, I could allow the government to choose any $x \in[0,1]$ as this would implicitly contemplate the possibility that it may be optimal to repay some amount but not all of it. However, as the fundamental issue is why a social welfare maximizing government repays its foreign debts at all, the focus will be on the dichotomic choice between default and repayment. However, it is important to bear in mind that the same forces that would enforce repayment when the decision is dichotomic will also enforce it when the government can choose the optimal amount of repayment. ${ }^{11}$

World financial markets are assumed perfectly competitive. Foreign creditors and all agents in the domestic economy, including the government, have access to a frictionless storage technology, so the international gross interest rate, $R_{w}$, is equal to 1 . That is, one unit of the good "stored" yields one unit the following period. Foreign creditors have large endowments relatively to the size of the domestic economy. Perfect competition between creditors will make the expected return on sovereign lending equal to the world interest rate in equilibrium. In other words, the zero expected profit condition for foreign creditors is given by:

$$
b=E(x R b)
$$

If the government were always to default, trivially, the only amount of lending consistent with the zero expected profit condition will be zero lending. If the government were to default in some states of the world and repay in others, for the zero expected profit condition to hold, it has to be the case that the interest rate of the debt contract, $R$, is larger than the world interest rate. So, the interest rate that the government will have to pay when borrowing from foreign creditors will be equal or larger than the world interest rate as a result of the default risk.

\footnotetext{
${ }^{11}$ The extension of the model to the case where $x \in[0,1]$ is straightforward.
} 


\subsection{Optimization and equilibrium}

As the model will be solved by backward induction, it is useful to present first the "third party" agents' problem, as they are the last group to make a decision. These agents maximize at time 1 their expected time 2 payoffs by choosing an action $a$ belonging to the compact set $A$ :

$$
\max _{a \in A} E_{1}[\pi(\theta, a) \mid x]
$$

where $\pi(\theta, a)$ is continuous and differentiable with respect to $a$. The following assumptions guarantee the existence of a unique solution increasing in the fundamentals to the "third party" agents' optimization problem:

A1: $\left.\frac{d \pi(\theta, a)}{d a}\right|_{a=0}>0, \frac{d^{2} \pi(\theta, a)}{d a^{2}}<0 \forall \theta$

A2: $\frac{d \pi(\bar{\theta}, a)}{d a}>\frac{d \pi(\underline{\theta}, a)}{d a}$

Many different stories could fit this optimization problem, an example would be foreign investors choosing the optimal amount of investment in the country. Under such interpretation $\pi(\theta, a)$ could be written as:

$$
\pi(\theta, a)=\theta f(a)-R_{w} a
$$

where $a$ would be the level of investment and $f(a)$ a production function satisfying Inada conditions, which guarantees that both A1 and A2 would hold. The first order condition for the foreign investors' problem would be given by:

$$
E_{1}\left[\theta f^{\prime}(a)\right]=1
$$

It becomes clear from this condition that if investors's beliefs about the fundamentals, $\theta$, are more optimistic, the chosen level of investment will be higher. Let $a^{*}=a(p \prime(x))$ denote the optimal choice of investors, given the government default decision, $x$.

The government's welfare function in reduced form is given by:

$$
W=W\left(\theta, a\left(p^{\prime}(x)\right), G, T r\right)
$$

where $W$ is continuous and differentiable, $G$ is the amount of public expenditures in the production of public goods, and $T r$ are exogenous government revenues net of debt payments made to foreign creditors, that is: $\operatorname{Tr}=T-x R b$. Note that this expresion implies that creditors cannot seize government revenues following a default, and that the only potential cost of a default for 
the government is the effect that it might have on foreign investors' beliefs and therefore on their actions. Also, as the only purpose of borrowing in this model is to finance the production of public goods, it will be the case that $G=b$.

This welfare function can be interpreted as the government maximizing the welfare of the representative agent in the domestic economy, where the agent's welfare depends on its time 2 consumption of both public and private goods, with the latter being a function of fundamentals, the level of foreign investment, $a$, and government transfers, $\operatorname{Tr} .{ }^{12}$

The following assumptions add some structure to the model:

A3: $\frac{d W\left(\theta, a\left(p^{\prime}(x)\right), G, T r\right)}{d a}>0 ; \frac{d W\left(\theta, a\left(p^{\prime}(x)\right), G, T r\right)}{d T r}>0 ; W\left(\bar{\theta}, a\left(p^{\prime}(x)\right), G, T r\right)>W\left(\underline{\theta}, a\left(p^{\prime}(x)\right), G, T r\right)$

A4: $\quad \frac{d W\left(\bar{\theta}, a\left(p^{\prime}(x)\right), G, T r\right)}{d a} \geq \frac{d W\left(\underline{\theta}, a\left(p^{\prime}(x)\right), G, T r\right)}{d a} ; \quad \frac{d W\left(\bar{\theta}, a\left(p^{\prime}(x)\right), G, T r\right)}{d T r} \leq \frac{d W\left(\underline{\theta}, a\left(p^{\prime}(x)\right), G, T r\right)}{d T r} \quad$ with at least one inequality

A5: $W\left(\theta, a\left(p^{\prime}(1)\right), G^{c}, \operatorname{Tr}(1)\right)<W\left(\theta, a\left(p^{\prime}(0)\right), G^{c}, \operatorname{Tr}(0)\right) \quad \forall \theta$, where $G^{c}$ is the optimal level of public spending under full commitment.

A3 states that an increase in the "third party" action (i.e. higher FDI), an increase in exogenous government revenues or lower debt repayments, or better fundamentals have a positive effect on welfare. Welfare could be increasing in FDI, as FDI may create jobs and the government might care about employment or wages of some not modeled domestic agents. Alternatively, the government might be able to seize a part of the output of the foreign investors' project, so the amount it can seize will depend on how much was invested. A4 will be crucial to establish a "single crossing property" in the model. It states that the increase in welfare generated by a change in "third party" agents' actions will be equal or higher when fundamentals are good, and that the cost of repaying when fundamentals are good will not be higher than when they are bad (with at least one inequality). The intuition behind these assumptions is straightforward. If third party agents are foreign investors, then the first inequality could be interpreted as stating that when fundamentals are better, investment is more productive, and as a result an increase in FDI generates a larger increase in output and welfare. ${ }^{13}$ The second inequality states that, although debt repayments are

\footnotetext{
${ }^{12}$ Interpreting $W\left(\theta, a\left(p^{\prime}(x)\right), G, T r\right)$ as the welfare of the representative domestic agent is not necessary for the results of the paper. For example, $W\left(\theta, a\left(p^{\prime}(x)\right), G, T r\right)$ could instead be the welfare function of a government maximizing its chances of being reelected (which could be a function of its production of public goods, FDI, fundamentals and transfers) and the results of the model would not be affected.

${ }^{13}$ In general, there would be two effects to take into account when analyzing how better fundamentals affect the effect of higher FDI on welfare. The first effect can be thought of as a substitution effect -it is more convenient to have more foreign investment when fundamentals are good as you are more productive-. The second effect, that appears with concavity, is a wealth effect -when fundamentals are good there is more output, so the welfare gain of having additional goods is smaller-. Both effects work in opposite directions. A4 requires the substitution effect to weakly dominate the wealth effect.
} 
not contingent on the fundamentals, the welfare cost of repaying might differ when fundamentals are good or bad. For example, under concavity of the welfare function, the welfare cost of repaying a given amount would be smaller when fundamentals are better as there are more goods available for consumption. For simplicity, it is useful to assume that all cross derivatives are zero. ${ }^{14}$

The final assumption, A5, states that the government will prefer to default on the level of debt corresponding to the optimal, full-commitment level of public expenditures. As welfare is increasing in public expenditures, $G$, this assumption implies that the borrowing constraint imposed by creditors will always bind. A consequence of this assumption is that the government will never choose to borrow and just save in the risk-free asset.

The government faces two decisions in the model. At time 0 it has to decide how much to borrow and spend in the production of a public good, and at time 1, once it has received its private information, it has to decide whether to repay or default on the debt "inherited" from time 0.The time 0 problem involves choosing the optimal level of debt and public expenditures before the private information is revealed:

$$
\begin{aligned}
& \max _{b, G} E\left[W\left(\theta, a\left(p^{\prime}(x)\right), G, T r\right)\right] \\
& \text { subject to } \\
b \leqslant & \bar{b} \\
G= & b \\
T r= & T-x R b \\
G \geq & 0
\end{aligned}
$$

where $\bar{b}$ is the maximum amount that foreign creditors are willing to lend. In the absence of any commitment problem the government would just equate the expected marginal return of investing in the production of the public good with the marginal cost of borrowing, but its borrowing will be constrained by its inability to commit to repay. ${ }^{15}$

The time 1 repayment/default decision can be characterized as follows:

$$
\begin{aligned}
& \max _{x \in\{0,1\}} W\left(\theta, a\left(p^{\prime}(x)\right), G, T r\right) \\
& \text { subject to } \\
T r= & T-x R b \\
T r \geq & 0
\end{aligned}
$$

\footnotetext{
${ }^{14}$ It is not difficult to extend the model to cases when this does not happen, but the presentation would become more cumbersome.

${ }^{15}$ The government resource contraint could also limit the ability of the government to borrow. However, in order to focus on the government incentives to repay, it is assumed that $\mathrm{T}$ is large enough.
} 
As international credit markets are perfectly competitive, foreign creditors' profits should be zero in expectation. The government appropriates any "surplus" that its dealing with foreign creditors creates. Foreign creditors' problem at time 0 can be written in reduced form as follows: ${ }^{16}$

$$
\begin{aligned}
& \max _{b} b \\
& \text { subject to } \\
& b=E[x b R]
\end{aligned}
$$

The equilibrium of this economy can be defined as follows:

Definition 1 A Perfect Bayesian equilibrium of this economy is a set of time 0 and time 1 borrowing, lending, and spending decisions, prices and beliefs:

$\left\{\left(\bar{b}, b^{*}, G^{*}\right),\left(x, a^{*}\right),\left(R^{*}\right), p^{\prime}(x)\right\}$ such that:

(E1) $\bar{b}$ is a solution to (8), $b^{*}, G^{*}$ are a solution to (7), $x$ is a solution to (6), and $a^{*}$ is a solution to (5) given prices

(E2) Markets clear: $E(x R)=1$

(E3) Beliefs, $p^{\prime}(x)$, are consistent with Bayes' rule

The strategy for each of the players (government, foreign creditors, foreign investors) is a mapping from their information sets that include all observed actions played by other players that move before them to each player action set. Note that as foreign investors make their time 1 decisions without observing the value of the fundamentals, they should update their beliefs about them and base their actions on the posterior beliefs, $p$, that condition on the government choices after observing the fundamentals.

\section{WHY DO GOVERNMENTS REPAY FOREIGN CREDITORS?}

The central question addressed in this paper is why governments ever repay foreign creditors? The presence of private information on the hands of the government can create incentives to repay. The information structure of the model is such that the repayment/default decision of the government may act as a signal revealing information to domestic and foreign agents alike about the

\footnotetext{
${ }^{16}$ The issue of how this amount of lending is then allocated between the different foreign creditors is irrelevant for the purpose of this paper.
} 
fundamentals of the economy. A default may negatively affect foreign investors ' beliefs about the fundamentals of the economy leading them to reduce their investment, and, through this channel, government welfare. This implies that defaults are potentially costly and, as a result, the government may have incentives to repay at least for some realizations of the fundamentals.

In order to formalize this intuition let's analyze in detail the time 1 repayment/default decision. At time 1, the government already knows what the fundamentals are, the level of government expenditures, $G$, the amount of sovereign debt, $b$ and the interest rate on government debt, $R$ are given by the time 0 decisions, and government revenues, $T$, are assumed exogenous and sufficient to repay the outstanding debt. In order to decide whether to repay or default on its sovereign debt, the government will compare the welfare that each of the two options will generate. For given levels of $\theta, G, b, R$ and $T$, the government will only repay if:

$$
W\left(\theta, a\left(p^{\prime}(1)\right), G, T-R b\right) \geq W\left(\theta, a\left(p^{\prime}(0)\right), G, T\right)
$$

The above expression makes clear the costs and benefits of repaying. The cost of repaying is given by the last argument of the function, namely a smaller amount of resources can be used for transfers, and the benefit of doing so by the second one, the impact on foreign investors beliefs. It follows that, in this model, the only reason why a government would repay is to affect expectations. If repaying does not reveal any information, it will not affect beliefs and foreign investors ' actions (i.e.: $\left.a\left(p^{\prime}(1)\right)=a\left(p^{\prime}(0)\right)\right)$, then the government will always be better off by defaulting on any outstanding amount of debt.

An implication of the assumptions of the model is that if a government finds optimal to repay when fundamentals are bad, then it will also find optimal to repay when they are good. The following Lemma formalizes this:

Lemma 1 (Lemma 1) For a given level of government expenditures, $G$, debt and interest rate, $R b$, if the government finds optimal to repay when fundamentals are bad ( $\underline{\theta})$, it will also do it when fundamentals are good $(\bar{\theta})$

\section{Proof. See Appendix}

The intuition for this result is straightforward. If the government finds optimal to repay when fundamentals are bad and the foreign investment is less productive (which implies it has a smaller impact on welfare given previous assumptions) and/or the cost of repaying is higher (i.e.: benefit from defaulting is higher), it must be the case that it also finds optimal to do it when fundamentals are good and foreign investment is more productive and the cost of repaying is lower. 
The following Lemma shows that there exists a positive level of debt for which the government will find optimal to repay only when fundamentals are good, and as a result the repayment/default decision fully reveals the state of the fundamentals.

Lemma 2 (Lemma 2) Assume beliefs are updated in such a way that: $p^{\prime}(1)>p^{\prime}(0)$. Then there exists a positive level of sovereign debt that the government will only be willing to repay if fundamentals are good.

Proof. See Appendix

The following proposition, building on the previous Lemmas, shows that there exists a separating equilibrium with positive sovereign borrowing in the model.

Proposition 1 (Proposition 1) There exists an equilibrium with positive sovereign borrowing where the government defaults when fundamentals are bad, and repays otherwise. In this equilibrium:

$p^{\prime}(0)=0$ and $p \prime(1)=1$

$R^{*}=\frac{1}{p}$

$b^{*}>0$ and, in particular it will be the one that makes: $W\left(\bar{\theta}, a(1), b^{*}, T-\frac{1}{p} b^{*}\right)-W\left(\bar{\theta}, a(0), b^{*}, T\right)=$ 0

Proof. See Appendix

The previous proposition shows that there exists an equilibrium for this model with positive sovereign borrowing in which the government will default when fundamentals are bad, and repay when they are good. The government repays to communicate information about the fundamentals to other agents in the economy, and in this way influences their expectations. In other words, the government repays out of concern of the effect of a default on expectations.

An implication of this separating equilibrium, consistent with the empirical evidence, is that the level of foreign direct investment will be lower following a default. The reason would be that a default will create concerns regarding the fundamentals of the economy and therefore will reduce the expected return on investment, discouraging foreing investors from investing in the country.

The separating equilibrium characterized above is not the only possible equilibrium of this economy. Another trivial equilibrium is one in which there is no lending to the government. A more interesting set of equilibria for this model is one in which there is a positive amount of 
sovereign debt and the government never defaults. ${ }^{17}$ The following proposition shows the existence of these pooling equilibria.

Proposition 2 (Proposition 2) For any set of posterior beliefs $p^{\prime}(1)=p$ and $p^{\prime}(0)<p$, there exist an equilibrium with positive sovereign borrowing in which the government always repays. In such equilibrium:

$$
R^{P *}=1
$$$$
b^{P *}>0 \text { and, in particular it will be the one that makes: } W\left(\bar{\theta}, a\left(p^{\prime}(1)\right), b^{P *}, T-b^{*}\right)-W\left(\bar{\theta}, a\left(p^{\prime}(0)\right), b^{P *}, T\right)=
$$

Proof. See Appendix

As it is usually the case in signaling models, these set of pooling equilibria are very sensitive to the off-equilibrium beliefs. For instance, it is immediate that there would be no pooling equilibrium if $p^{\prime}(0) \geq p$, as in such a case there would be no information gain from repaying.

Introducing a costless signal in the model, such as a government announcement on the fundamentals, will be irrelevant for the equilibrium. The intuition is straight forward. Both under good and bad fundamentals, the government would like foreign investors to believe that fundamentals are good. Given that the announcement is costless, it is costless for a government with bad fundametnals to mimic the announcement of a good government, so the announcement by itself cannot affect beliefs. The announcement would just be cheap talk and not reveal any information. ${ }^{18}$

The introduction of an alternative costly signal in the model is a more interesting extension. There are two main cases to analyze on this regard. The more realistic one is a situation in which the private information has multiple dimensions and there are multiple signals available to the government. In such a context, it is likely that the government will need to undertake multiple actions to signal its private information, including debt repayment. ${ }^{19}$ This paper tries to capture in a simpler way this sort of story.

A second case of theoretical interest is when there exists an alternative costly signal, $z$, but the private information is unidimensional as in the model. ${ }^{20}$ In this case, the "good" government will choose the signal that allows it to signal its type in a cheaper way. That is, there might be

\footnotetext{
${ }^{17}$ There are also other possible separating equilibria in this economy, but it is straight forward to show that the one characterized above is the only one satisfying Cho-Kreps intuitive criterion. Furthermore, without further assumptions on the welfare function, it is not possible to rule out the presence of equilibria in mixed strategies. In this equilibria, a good government might default (or a bad government repay) with some positive probability.

${ }^{18}$ This result is not surpising as the government and foreign investors ' objective functions are not sufficiently similar.

${ }^{19}$ There are very few attempts in the theoretical literature to solve problems of this kind. Quinzi and Rochet (1985), Engers (1987) and Bagwell (2006) are the better known ones.

${ }^{20}$ This case resembles the analysis in the industrial organization literature on advertising as a signal of quality and the limit pricing literature (in particular, there are similarities with Milgrom-Roberts (1986))
} 
some level $z_{s}$ for which the "bad" government will choose not to undertake it, even if by doing $z_{s}$ it induces the belief that it is a "good" government. The "good" government will compare the level of welfare that it can achieve signaling through $z_{s}$ and through repaying and decide accordingly.

An interesting feature of the model is that signaling with debt is ex-ante efficient. The reason is that welfare is increasing in the amount of government spending (as long as $G<G^{c}$ ), which means that welfare is increasing in the amount of borrowing that the government can undertake at time 0 . So, even in the presence of alternative costly signals that the government might use at time 1 , the government would like to commit at time 0 to use repayment as a signal. In the absence of this commitment technology, the presence of alternative costly signals might end up reducing welfare.

If the variability of $\theta$ captures the degree of asymmetric information in an economy, then an implication of the model is that the larger the degree of asymmetric information the larger the amount of borrowing that the government could undertake. Interpreting $\theta$ as the ability of governments to improve fundamentals would imply that emerging countries, where $\theta$ is likely to vary more, should be able to sustain a larger amount of debt than deveoloped ones. This seems a counterintuitive implication of the model. However, it is important to keep in mind two things. First, informational costs of defaults could coexist with a reputational story (i.e.: exclusion from credit markets) or sanctions story. If any of the latter two were larger for developed countries then the overall level of borrowing that governments from developed countries could achieve would still be larger.

Within the information argument, a slightly more complicated version of the model could reconcile this argument with the different ability of governments from emerging and developed countries to borrow from abroad. For example, assume that the government does not observe the true value of $\theta$, but a noisy signal about it, $z=\theta+\varepsilon$, where $\varepsilon$ constitutes the random noise of the signal. Let's assume that the variance of $\theta$ (i.e. the degree of asymmetric information) is larger in emerging countries, while the opposite happens with the noise of the signal, $\varepsilon$. This could imply, depending on the parameters, that the repayment/default decision would convey more information in developed countries. If this were the case, governments in developed countries would be able to borrow more than those in emerging ones.

As it is usually the case with signaling games the results crucially depend on the specification of the timing of events. The model assumes that the government receives its private information at time 1, after it had borrowed and before it has to repay/default. Trivially, if the information were to be received after the moment when the government has to repay/default, then the information story would not hold. However, given that the maturity of the contracts is endogenous in the model, it seems natural to believe that the maturity may be adjusted so that the government has incentives to repay. That is, the results of the paper would still hold as long as the information is 
not received in the final period after all other events have taken place.

If the government were to receive its private information at time 0 , the results of the model would still hold. If the government were to get its private information after borrowing at time 0 , trivially nothing would change. A more interesting case would be one in which the government receives its private information at the beginning of the game at time 0 , before borrowing. In this case, the borrowing decision may also reveal its private information. Assume that in the benchmark model the government finds optimal to borrow different amounts when the state is good and when it is bad. If the amount borrowed were to reveal its private information, then given the assumptions of the model, the government would have no incentives to repay and it will always default on its debts. As a result, foreign creditors would not lend to the government. As welfare is increasing in the amount borrowed, the government will maximize welfare by not revealing any information through the amount borrowed, as this would allow the government to reveal the information through the repayment/default decision. And, this in turn, would provide incentives to repay.

\section{CONCLUSIONS}

For the last twenty five years the sovereign debt literature has tried to solve a simple puzzle. Given the limited enforceability of sovereign debt contracts, why do sovereign governments ever repay foreign creditors? In this paper I have suggested an explanation to this question based on information revelation. The government uses debt repayments as a signaling device to reveal private information. One likely source of private information, particularly in emerging markets, is the ability of the government to positively affect the fundamentals of the economy. In the model the government repays to influence agents' expectations about this ability.

The paper finds general conditions under which this information mechanism could sustain a positive amount of sovereign borrowing in a finite horizon. It shows that both a separating equilibrium in which "bad" governments default and a pooling one in which the government will never default.

I illustrate the role of signaling in sovereign debt repayment with an example based on the effect of a default on the beliefs of foreign investors. However, it is clear that there could be other channels through which sovereign defaults, affecting expectations, may impact on the domestic economy. Given the empirical evidence, it seems natural to think about a channel linking sovereign defaults with currency crises, for example. The exploration of these other channels and the policy implications that result from them remains a pending issue, and constitutes a crucial step to obtain realistic estimates of the cost of sovereign defaults. 


\section{REFERENCES}

\section{References}

[1] Amador, M., 2003. A Political Economy Model of Sovereign Debt Repayment. Mimeo MIT

[2] Bagwell, K., 2006. Signalling and entry deterrant: A Multidimensional Analysis. Mimeo Columbia University

[3] Bulow, J., Rogoff, K., 1989a. Sovereign Debt: Is to Forgive to Forget? American Economic Review, Vol. 79 pp.43-50, June 1989

[4] Cole, H., Dow J., English, W., 1994. Default, settlement, and signaling: lending resumption in a reputational model of sovereign debt. Federal Reserve Bank of Minneapolis, Research Department Staff Report 180, September 1994.

[5] Cole, H., Kehoe, P., 1997. Reputation Spillovers across Relationships: Reviving Reputation Models of International Debt. Federal Reserve Bank of Minneapolis Quarterly Review. Vol. 21, No. 1, Winter 1997, pp. 21-30.

[6] Cole, H., Kehoe, P., 1998. Models of Sovereign Debt: Partial versus General Reputations. International Economic Review 39, pp. 55-70.

[7] Eaton, J., 1995. Sovereign Debt, Reputation and Credit Terms. International Journal of Finance Economics Vol.1, April 1995, pp 25-35.

[8] Eaton, J., Fernandez, R., 1995. Sovereign debt. NBER, Working Paper 5131, May 1995.

[9] Eaton, J. Gersovitz, M., 1981, Debt with Potential Repudiation: Theoretical and Empirical Analysis. Review of Economic Studies, 48, pp. 289-309.

[10] Engers, M., 1987. Singalling with many signals. Econometrica, Volume 55(3), 1987, pp.663-674.

[11] Gavin, M., Werneck, V., 2002. Brazil Update. UBS Warburg Latin America Economic Comment, July 52002.

[12] Kletzer, K., Wright, B., 2000. Sovereign Debt as Intertemporal Barter. The American Economic Review, Vol. 90, June 2000.

[13] Kocherlakota, N., 1996. Implications of efficient risk sharing without commitment. The Review of Economic Studies 63, pp.595-610. 
[14] Ligon, E., Thomas, J., Worral, T., 2000. Mutual insurance, indivual savings, and limited commitment. Review of Economic Dynamics 3, pp.216-246

[15] Martinez, J., Sandleris, G., 2005. Is it Punishment? Sovereign Defaults and the Decline in Trade. Mimeo Columbia University

[16] Milgrom, P., Roberts, J., 1986. Price and Advertising Singals of Product Quality. Journal of Political Economy, Volume 94(4), 1986 pp.796-821

[17] Quinzi, M., Rochet, J., 1985. Multidimensional Signalling. Journal of Mathematical Economics, Volume 14, 1985, pp. 261-284

[18] Thomas, J., Worrall, T., 1990. Income fluctuation and Asymmetric Information: An example of a Repeated Principal Agent Problem. Journal of Economic Theory, Vol. 51, pp. 367-390.

[19] Wright, M., 2002. Reputation and Sovereign Debt. Mimeo MIT. 


\section{APPENDIX}

\subsection{Proofs (available only online)}

Proof. [Lemma 1] If the government chooses to repay when fundamentals are bad, then it implies that:

$W\left(\underline{\theta}, a\left(p^{\prime}(1)\right), G, T-R b\right) \geq W\left(\underline{\theta}, a\left(p^{\prime}(0)\right), G, T\right)$

But, from A4 $\frac{d W\left(\bar{\theta}, a\left(p^{\prime}(x)\right), G, T r\right)}{d a} \geq \frac{d W\left(\underline{\theta}, a\left(p^{\prime}(x)\right), G, T r\right)}{d a} \quad$ and $\quad \frac{d W\left(\bar{\theta}, a\left(p^{\prime}(x)\right), G, T r\right)}{d T r} \leq \frac{d W\left(\underline{\theta}, a\left(p^{\prime}(x)\right), G, T r\right)}{d T r}$ with at least one inequality

Assume the first one only holds with inequality. Then, $\quad W\left(\underline{\theta}, a\left(p^{\prime}(1)\right), G, T-R b\right)-$ $W\left(\underline{\theta}, a\left(p^{\prime}(0)\right), G, T\right) \leq W\left(\bar{\theta}, a\left(p^{\prime}(1)\right), G, T-R b\right)-W\left(\bar{\theta}, a\left(p^{\prime}(0)\right), G, T\right)$ with equality if $p^{\prime}(1)=p^{\prime}(0)$

So, the welfare gain of repaying when fundamentals are good will never be smaller than when they are bad.

A similar reasoning would hold if $\frac{d w\left(\bar{\theta}, T+S_{0}-x R_{g} b_{g}\right)}{d\left(T+S_{0}-x R_{g} b_{g}\right)} \leq \frac{d w\left(\underline{\theta}, T+S_{0}-x R_{g} b_{g}\right)}{d\left(T+S_{0}-x R_{g} b_{g}\right)}$ were holding with inequailty.

Proof. [Lemma 2] From Lemma 1 we know that $W\left(\bar{\theta}, a\left(p^{\prime}(1)\right), G, T-R b\right)-W\left(\bar{\theta}, a\left(p^{\prime}(0)\right), G, T\right)>$ $W\left(\underline{\theta}, a\left(p^{\prime}(1)\right), G, T-R b\right)-W\left(\underline{\theta}, a\left(p^{\prime}(0)\right), G, T\right)$ if $p^{\prime}(1)>p^{\prime}(0)$. Note that if $b R=0$ then $W\left(\underline{\theta}, a\left(p^{\prime}(1)\right), G, T-\right.$ $R b)-W\left(\underline{\theta}, a\left(p^{\prime}(0)\right), G, T\right)>0$ given the assumption that $p^{\prime}(1)>p^{\prime}(0)$, so by continuity $\exists b R>0$ for which $W\left(\underline{\theta}, a\left(p^{\prime}(1)\right), G, T-R b\right)-W\left(\underline{\theta}, a\left(p^{\prime}(0)\right), G, T\right)>b R$. This implies that even under bad fundamentals the government will be willing to make some repayments as long as the amount of debt is low enough though still positive. Pick any positive level of debt $b$ and interest rate $R$ such that

$W\left(\bar{\theta}, a\left(p^{\prime}(1)\right), G, T-R b\right)-W\left(\bar{\theta}, a\left(p^{\prime}(0)\right), G, T\right) \geq b R>W\left(\underline{\theta}, a\left(p^{\prime}(1)\right), G, T-R b\right)-W\left(\underline{\theta}, a\left(p^{\prime}(0)\right), G, T\right)$

It is clear that for any such level of debt and interest rate the government will only find optimal to repay when fundamentals are good and that $b R>0$.

Proof. [Proposition 1] The proof of this proposition involves 4 steps.

i. There exists a solution to agents individual problems

As all agents are maximizing continuous functions over compact sets, from Weierstrass theorem there exists a maximum.

ii. There are updating rules of private sector beliefs for which the government will repay a positive amount of debt

This follows from Lemma 2

iii. The updating of beliefs is consistent

In the previous step I have assumed that $p^{\prime}(1)>p^{\prime}(0)$. In particular, let $p^{\prime}(1)=1$ and $p^{\prime}(0)=0$. That is, after a default beliefs are that fundamentals are bad, and after a repayment 
beliefs are that fundamentals are good. Given this updating rule, from Lemma 2 there exist strictly positive levels of debt for which the government will repay only when fundamentals are good and default when they are bad. As a result the updated beliefs will be correct on equilibrium.

iv. In this equilibrium: $R^{*}=\frac{1}{p}$ and $b^{*}$ will be such that $W\left(\bar{\theta}, a\left(p^{\prime}(1)\right), b^{*}, T-\frac{1}{p} b^{*}\right)-$ $W\left(\bar{\theta}, a\left(p^{\prime}(0)\right), b^{*}, T\right)=0$

Perfect competition in international credit markets implies that foreign creditors will lend to the government any amount that satisfies their zero expected profit condition. The maximum amount that the government can commit to repay (i.e.: the incentive compatibility constraint) when fundamentals are good is the one that would make the government indifferent between repaying and defaulting when fundamentals are good, which is given by: $W\left(\bar{\theta}, a\left(p^{\prime}(1)\right), b^{*}, T-\frac{1}{p} b^{*}\right)-$ $W\left(\bar{\theta}, a\left(p^{\prime}(0)\right), b^{*}, T\right)=0$

From A5 the borrowing constraint will bind, so the government will borrow as much as possible, which implies that $b^{*}=\bar{b}$.

In addition, for the zero expected profit condition to hold:

$b^{*}=E\left[x R^{*} b^{*}\right]$

As the government will only repay when fundamentals are good and this happens with probability $p$ :

$E[x R b]=p R^{*} b^{*}$

So, from the two previous expressions: $R=\frac{1}{p}$

Proof. [Proposition 2] From the previous proof, there exists a solution to agents' problems.

Assume that posterior beliefs are:

$p^{\prime}(1)=p$ and $p^{\prime}(0)<p$

From lemma 1: $W\left(\bar{\theta}, a\left(p^{\prime}(1)\right), b, T-R b\right)-W\left(\bar{\theta}, a\left(p^{\prime}(0)\right), b, T\right)>W\left(\underline{\theta}, a\left(p^{\prime}(1)\right), b, T-R b\right)-$ $W\left(\underline{\theta}, a\left(p^{\prime}(0)\right), b, T\right)$

And from lemma 2 , there exists $R b>0$ such that:

$W\left(\underline{\theta}, a\left(p^{\prime}(1)\right), b, T-R b\right)-W\left(\underline{\theta}, a\left(p^{\prime}(0)\right), b, T\right)>0$

Then for those $R b$ that satisfy this, the government will find optimal to repay both when fundamentals are good and when they are bad. This in turn implies that beliefs are correct on equilibrium (there is no information revealed by a repayment), and that a default will be an offequilibrium event. So, the posterior beliefs conditional on default are not pinned down.

For those $R b$ where the government will never default, perfect competition in international credit markets guarantees that $R^{P *}=R_{w}=1$. As a result the maximum amount the government will be able to borrow, $\bar{b}^{P}$, will be given by:

$W\left(\underline{\theta}, a\left(p^{\prime}(1)\right), \bar{b}^{P}, T-R \bar{b}^{P}\right)-W\left(\underline{\theta}, a\left(p^{\prime}(0)\right), \bar{b}^{P}, T\right)=0$

And as in Proposition 1: $b^{P *}=\bar{b}^{P}$ 